\title{
Implementation of Creative Education Policy in Russian Higher Education Curricula
}

\author{
Tamara Savelyeva \\ Department of International Education and Lifelong Learning, The Hong Kong Institute of Education, \\ Hong Kong, China \\ Email: tamara@ied.edu.hk
}

Received December $18^{\text {th }}, 2013$; revised January $18^{\text {th }}, 2014$; accepted January $25^{\text {th }}, 2014$

Copyright (C 2014 Tamara Savelyeva. This is an open access article distributed under the Creative Commons Attribution License, which permits unrestricted use, distribution, and reproduction in any medium, provided the original work is properly cited. In accordance of the Creative Commons Attribution License all Copyrights (C) 2014 are reserved for SCIRP and the owner of the intellectual property Tamara Savelyeva. All Copyright (c) 2014 are guarded by law and by SCIRP as a guardian.

An ongoing restructuring of Russian higher education prioritizes development of a "creative educational system" as one of its policy directions. Following this recent policy mandate, Russian universities have been introducing new curricular models, which they adopt from the Western academic school of teaching and learning. However, Western-designed curricular novelties and methodologies that support creative education policies have been criticized for lacking success in Russian HE due to key differences in traditional cultures of educational systems. How do faculty facilitate curricular changes in support of the creative education policy? This study addresses this question by exploring the implementation of a specific curricular module in the field of creative education - the Sustainability project in two Russian universities. The resulting descriptive model comprises antecedents, processes, and contents of the project implementation under three broad categories of the university restructuring: organization, environment, and relation. I discuss the findings in terms of the two important characteristics of the resulted curricular implementation model: (1) the culturally sensitive nature of creative education curricular adaptation in post-Soviet higher education, and (2) non-linearity of the curricular education policy enactment in Russian university classrooms.

\author{
Keywords: Cultural Diversification Framework; Creativity Education; Non-Linearity; Curricular \\ Implementation Model; Policy Enactment; Post-Soviet Environment; Re-Structuring; Russian \\ Higher Education
}

\section{Introduction}

Educational restructuring (Gumport, 2000) ${ }^{1}$ is not a choice but an imperative force of a "globalized" reality in many countries. Within the educational realms of Russian higher education (HE), institutional policy emphasis on university restructuring goes back to the adoption - on Dec. 29, 2012 — of the new Federal Educational Law. Since the enactment of this law, Russian universities have been officially operating in a new policy environment, driven by the philosophies of economic rationalism (Pusey, 1991) and managerialism (Pollitt, 1990). As a result, the demand for a "creative educational system" in Russian HE considers the requirements of the market-driven educational policy environment and emphasizes scarcity, competition (Marginson, 1993), accountability, excellence, and efficiency (Welch, 1996). New to Russian faculty and educational administrators, the 3E (efficiency, excellence, and economy) academic value system (Welch, 1998) requires universities to align their traditional curricular structures and praxis with the newly adopted policy guidelines. The demand for a "creative educational system", which followed these recent shifts in the philosophy and administration of Russian HE, led to drastic

\footnotetext{
${ }^{1}$ Gumport viewed university restructuring as a complex phenomenon that involves rethinking of the ways universities allocate recourses, generate revenue, and align their structures with the external demands of the society.
}

changes in the universities' curricular structures and methodologies. How do universities under condition of restructuring promote creative education methodologies? How do faculty facilitate curricular changes in support of the creative education policy?

My study is based on the assumption that in Russian university environments, faculty and students approach a mandatory implementation of the creative education policy agenda with a baggage of cultural beliefs and knowledge of their traditional educational systems. This determines their reasoning behind adapting a particular curricular project and teaching-learning methods in their courses and classrooms, and, most importantly, defines the longevity of the implemented project. By emphasizing the role of culture in curricular practices, I only aim to acknowledge, without further exploration, that curricular practices and their implementation depend on a societal culture, within which they are performed.

In this study, I address the problem of implementing new curricular modules in support of the creative education policies in universities under condition of restructuring. I propose a descriptive model, which consists of three contextual categories of curricular implementation in the restructuring university: organizational, environmental, and relational. This model was created based on the results of a two-year empirical study of a 
Sustainability project, a creative education initiative piloted by the faculty and students at two Russian universities in 2010. Drawing on the project's data, I suggest that the resulted model of curricular implementation might be best articulated within the research frames that reference two features: (1) cultural sensitivity of curricular adaptation and (2) non-linearity of the curricular education policy enactment in Russian university classrooms. Before discussing the study, I would like to introduce two themes that provide a broader context to the inquiry. One of the themes has to do with a historical account of the creative education policy and its effects on a curricular structure in Russia; the other has to do with the challenges of implementing creative education agenda due to cultural differences between Russian and Western academic traditions.

\section{Creative Education in Russian HE}

Among many new curricular areas recently introduced into the Russian system of HE (e.g. business management, market economics, sociology and political studies), creative education did not stand alone as a separate area of study. Treated as a methodological package to accompany Western-designed business education curricula, creative education at first stayed within the borders of Russian business schools. Consequently, creative education has first emerged as a new curricular methodology, which aimed to align the educational policies for building a "creative educational system" with the universities' classroom practices. Coming from a business-education sector of the restructuring university system, creative education built up its conceptual frames by initiating academic discourses about methodological applications of the Western-designed management training programs for academic systems undergoing restructuring. Resulting from a brief exchange of academic opinions in Russian academic meetings, the creative education was connected with a philosophical current of American pragmatism and given new terminological tools to operate in the academic area of educational policy and administration in Russia. Following the foundations of creative education of John Guilford (1950), creative education in Russia was broadly defined as a process of “organizing and managing one's creative process for the purpose of producing a required [creative] product" (Arich, 2008). A new Russian term "kreativnost," meaning "creative [education]" was directly translated from the American English dictionary to explain the new phenomena in the educational policy arena of inquiry; for clarity, it was compared with the traditional use of a creativity concept in the Russian school of developmental psychology (Freud, Fromm, Maslow, etc.). A successful business educator Elena Arich (2008), points out the difference between creativity and creative education as follows:

Creativity and creative [education] are not synonyms. A classic creativity discourse approaches the phenomena as a free motion of an inspired person, that has to do with inspirational factors, range of creative abilities the person possess, his or her beliefs, and the traditions that the person follows. In contrast, the idea of creative education views the phenomena from a standpoint of pure pragmatism, considering practical grounds for any creative motion. Under the framework of pragmatism, an initial creative motion of a person has to do with his or her knowledge of why, for whom, how, and what exactly needs to be created (p. 5).
In accordance, the importance of creative education to the pursuit of the university restructuring objectives had been clearly acknowledged and accepted-though not thoroughly theorized or contextualized-within the management-oriented realms of educational policy and administration fields of study. The Russian Academy of Natural Sciences, the most influential scientific structure of the Russian Federation, defined goals, means, and set the ends of creative education for meeting the newly established policy directions. According to Gordashnokov and Osin (2009), creative education aims to "awake one's creative powers and develop one's inherent creativity; cultivate boldness of thought and strong belief in one's creative potential; nurture ability to generate new and exciting ideas of universal value, which shall not harm nature, and the inherent need for a creative way of life” (p. 44). In Russian context, creative education is approached as a process with four characteristics: (1) continuity and life-long orientation; (2) active student involvement into learning; (3) independent management of creative proesses, and (4) alignment between creative knowledge and relevant assessment criteria (Gordashnokov \& Osin, 2009). Applied to the HE system, creative education in Russian HE can be established by means of:

- Information Technology (IT). IT can be employed for a didactic support of intellectual processes and critical thinking;

- Holistic educational strategies. Holistic nature of knowledge, which one acquires through university education, can be achieved by integrating disciplinary resources specified in federal educational standards;

- Emphasis on intellectuality. Intellectual approach to creative problem solving might include such strategies as identification and formulation of a creative task, targeted search for various solutions, evaluation and choice of optimal solutions, to match the educational standards;

- Docendo docimus principle. Applying the "learning while teaching” principle to teaching and learning helps monitor and assess progress of a creative activity;

- Integration of theoretical and methodological aspects of creativity for developing professional curiosity and occupational excellence.

The policy move toward a "creative educational system" not only proposed clear means of implementing creative education at universities, but also proposed assessment criteria to monitor the process. Lonchakov (2004) appeals to principles of holism, uncertainty, and systemic analysis and proposes two assessment criteria to monitor students' creative learning: students are able to perform a systemic analysis of a problem by deriving a core from a complex issue, formulating the problem, and managing the issue in a non-standard way to reach the best possible solution.

Creative education is also considered a priority for nurturing highly qualified faculty teachers and researchers. The practical model of creative education relies on a gradual implementation of new Western-designed teaching and assessment methodologies into existing university curricula.

While Russia has been displaying strong values and orientations toward the adaptation of Western-designed curricular modules in its educational system, it faces strong cultural barriers to a successful policy implementation. One of the barriers, which has implications for the HE system in Russia, is the history of collectivism, as it defines structures of a former Soviet Russian society. Unlike Western individualistic systems of 
teaching and learning, the traditional educational system in past Russia carried the goal of upbringing a whole-round person who is capable of effacing an individual freedom for the sake of the collective good. In classrooms, the collectivism principle manifested in an application of "whole-class" teaching and assessment strategies, serving an entire class proceeded toward a common collective goal. The Russian curricula had less emphasis on an ideal of an individual learner, whereas learnercentered curricular strategies were tied to a greater collective outcome. A drastic surge of globalization has brought about an instant change of the collectivism-oriented curricular methodologies and strategies toward more individualistic teaching and personalized learning. However, years after, individualistic teaching and learning remains slow paced and sharply criticized in Russian society. As a result, Russian universities have failed to fully introduce and accommodate creative education-related courses and initiatives. An additional problem is that Russian faculty simply had no time to adapt new curricular methodologies and adjust their programs to the new creative education agenda of their universities.

The proposed study timely follows up a policy aspect of university restructuring that requires an installment of a "creative educational system" in Russia. Under condition of restructuring, faculty are required to perform a quick adaptation to the new curricular models, methods, and initiatives. However, their access to information about what creative education really is and what new creative education methodology demands of them is very limited. Creative education, as a method and as a concept, is not taught in faculty training programs or widely used in universities. Making faculty and students work with a customized version of creative education curricula allowed me to gain insightful knowledge about how to sustain the new methodology in Russian university classrooms. The study also fulfilled the demand for soft, non-revolutionary re-enactment of new policies in university curricula in the HE institutions under condition of restructuring.

\section{Research Scope}

I used the case of the Sustainability project as an example of creative education curricular implementation in Russian universities. The project was launched in 2010 in two Russian universities, and it included one undergraduate-level course, collaboratively taught by Russian students and faculty with four other universities from the US, China, Australia, and Latin America The course included extensive use of Western-designed methodologies, such as case studies, on-line communication via Web 2.0 platform (Ning social network), student-led international videoconferences, and alternative assessment methods. The two research objectives of my study were: (1) to determine the aspects of the creative education initiative, which enabled its steady implementation over a period of time in the university under condition of restructuring; and (2) provide a description of contextual restructuring categories, which allowed faculty to adapt the creative education policy and facilitate changes in their curricular methods.

\section{Research Design}

I conducted the descriptive study of the Sustainability curricular initiative using a qualitative research design to provide a detailed and rich description of the contextual restructuring categories that allowed faculty to adapt the creative education policy and facilitate changes in their curricular methods. I situated the study within one of the streams of the organizational change conceptual framework (De Ven \& Huber, 1990) and focused on antecedents and consequences of change in university structure in relation to implementation of the creative education course into university classrooms.

\section{Instrument and Data Collection}

The survey instrument consisted of an open-ended questionnaire based upon the data about curricular implementations and restructuring available in the literature. For observations, I adapted and modified the Cresswell (2003) template by including specific items to capture instances of curricular implementation and adaptation in a university classroom. My choice of the observation items reflected the data derived from the survey responses. For the document analysis, I used a summary form adapted from Miles and Huberman (1994). The paper and on-line survey questionnaire were distributed as part of the course evaluation package at the end of the academic year. I conducted the observation and document analyses of the Sustainability curricular initiative during the fall 2009-spring 2010 semesters at the two universities in Russia.

\section{Data Analysis Procedure}

Data analysis began as soon as I had access to documents. I analyzed the first survey transcript using an open-coding feature of the NVivo ${ }^{\circledR}$ qualitative data analysis software, which allowed me to code interview and observation passages in the margins. First, I broke down the data for the appearance of patterns and themes. Second, I analyzed and open-coded the resulted categories into "thought units” (Butterfield, Reed, \& Lemak, 2004). I applied a coding-recoding strategy to my analysis to make sure my findings are dependable. Next, I grouped together the emerging coding categories of codes using an axial coding strategy to ensure the similarity of "thought units" within categories and, at the same time, the greatest difference among them. Finally, I further collapsed some of these codes and derived categories for creative education curricular implementation at the university under condition of restructuring.

\section{Findings: The Descriptive Model of Creative Education Curricular Implementation}

The findings from this study revealed three broad contextual categories of creative education curricular implementation in Russian universities: organization, environment, and relation (Figure 1). I interpreted the sub-themes, which emerged within each contextual category, through the relevant theoretical frameworks of organizational theory. The first organization category included sub-themes of structural adaptation and institutional survival; the environment category included subthemes of project transparency and flexible project dynamics; and the relation category included sub-themes of internal and external, formal and informal relationships.

\section{Organization}

Under this category, I put issues related to the university's internal management processes that either promoted or limited coordination, operation, and implementation of the Sustainability creative education initiative. Although classic organizational 


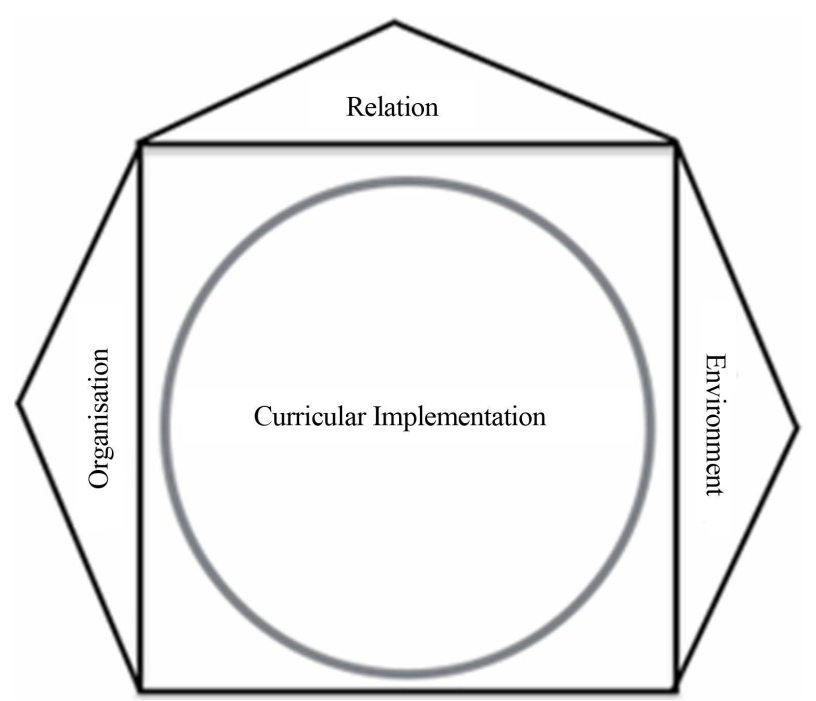

Figure 1.

Contextual categories of creative education curricular implementation.

theory stresses an importance of administrative control and managerial coordination within formal educational structures (Lǽggard \& Bindslev, 2006), this finding points out a different motivator for welcoming creative education methodologies into Russian university classrooms. The faculty's autonomy and lack of administrative pressure to implement the new policy stimulated their openness to the new, previously unknown ways of teaching. Without formal enforcement, faculty tested, modified, and adapted the creative education initiative due to their natural curiosity and high professional standards. Collaborating with other universities helped faculty to establish themselves as "global" players in the HE arena. They used the new methodologies following an example of their colleagues from different countries, and managed the project collaboratively within their institutions. The transparency of the project structure and its flexible dynamics were essential to ensure participants' commitment to the task of implementation. In reverse, lack of transparency to the managerial staff and faculty themselves, in some instances, have slowed down the implementation of the course. Explaining the unusual curricular structure of the new course and its methods to the participating faculty aided their involvement. However, formal "marketing" of the course's innovative features (a new case study methodology, different assessment techniques, and the use of social networking) to university administration would speed the process of implementation even further. Answering such questions as-Why did we choose this design for the course? Why are we using case studies and student assessments? Who are our sponsors? - prior the beginning of the course would address a more general issue of making the entire process of designing and operating the initiative more comprehensive.

\section{Environment}

Under the environmental category, I classified "externalities," or issues related to the participants' awareness about the external challenges, pressures, and causes of the university restructuring. Generally, the participants responded with skepticism to the idea of global competitiveness as a driving motivator of curricular change in their university. The administrative 3E (economy, effectiveness, and efficiency) focus of creative education policy was not totally rejected, but rather taken as irrelevant to classroom activities of the teaching faculty. Faculty justified the reasons for them implementing the course with such motivators, as their personal professional standards and academic principles. This finding goes against existing research arguments about university restructuring, which list competition (Smart \& Hitt, 1994), policy changes, and lack of resources (Meyer, Brooks, \& Goes, 1990) as triggers for faculty to bring change into the classroom. At the level of curricular implementation and in the minds of the teaching faculty, creative education was not connected with the changes in educational policies and university's responses to externalities. Students, on the other hand, viewed the course novelties as part of their tuition pay-off, and they were, in some instances, concerned with the faculty not arranging even more curricular "fit" with their schedule, living location, translation, travel plans etc. In this regard, some students behaved as outsiders, projecting the new course methodologies as new "products" that the university was "selling" to them at the costs of their tuition. Externalities, therefore, did not trigger a massive implementation of creative education methodologies in the classrooms, but were present in students' attitudes about the course organization and its purpose. The faculty's notion of "external” included federal and state governing bodies and global agencies, such as World Bank. In contrast, the students' notions of "externalities" were much more localized, and included industries and potential regional employers. This difference between faculty and students' understanding of "externalities" might be viewed as a result of recent "commercialization of Russian HE, and an attempt to treat students as "customers" and "consumers." In this sense, students' limited view of what "externalities" shaped their course experiences reflects their stance as customers to a new educational product-creative education. Students' stance as "passive recipients of whatever the institute decides to dish out" (Schwartzman, 1995: p. 7), points out a problem of "marketization” of education and its influence on students' involvement into shaping the curricular changes at the university. The faculty's larger notion of "externalities" features another effect of "marketization": faculty invest more into exploration of the new methodologies. Although the research literature (Dill \& Sporn, 1995) reports globalization and academic competitiveness as triggers for restructuring, the findings of this study suggest that the faculty has changed its curricular practices out of professional curiosity and intrinsic academic beliefs. This finding contradicts much of the literature that criticizes the marketization forces and the resulting HE competitiveness (Dill, 1997) by providing empirical evidence that the "marketization" and an emphasis on globalization and competition might be positive and encourage implementation of new curricula in universities.

\section{Relation}

Under this category, I classified the importance of internal-external, formal-informal relationships in the process of course implementation. The research not only shows the essential role of the relationships, both professional and personal, in implementing creative education policy in the classrooms, but also describes the dynamic of this process. So, the change from formal to informal mode of relation among the participants brought about changes in the classroom practices and made the 
process more interactive. For example, a shift from an official control over the course implementation by university officials to informal participants' self-reporting boosted up the speed of faculty experimenting with the new features of the course. They invited faculty members from other institutions to be part of their methodological experiments and used social networking to solidify the fluent communication and visibility of all the participants. Online social networking reengaged the participants into the conversation about the educational matters, and took their discussions beyond the topic of creative education. At the theoretical level, this finding supports the concepts of relational cohesion, where repeated exchanges among participants serve as a unifying force, enhance commitment, and reduce uncertainty (Lawler \& Yoon, 1993).

\section{Discussion}

The two important characteristics of the resulted curricular implementation model included (1) the culturally sensitive nature of creative education curricular adaptation and (2) nonlinearity of the curricular education policy enactment in Russian university classrooms. These characteristics suggest that a phenomenon of creative education policy implementation might be best articulated within social frameworks of cultural diversity, which complement the organizational research approach used in studies of educational restructuring. These two features of the resulted model also open new interpretation venues for a descriptive modeling method in studies of university restructuring.

The first feature of the resulted model suggests that the issue of a curricular innovation implementation in post-Soviet universities lies in the area of diverse educational cultures that is conceptually different from the area of organizational research. Contemporary researchers of the policy implementation arena devote much attention to organizational aspects of fostering curricular changes in the university classrooms (Savelyeva, 2013), organizational frameworks alone might be insufficient for explaining changes in educational systems, which were established based on the dramatically different principles of a non-market economy and a politically different social order. Established at the break of the Socialist revolution in 1918, the Russian educational system aimed for a collective good to build a new class-free society. The current restructuring of this wellstructured system, which functioned in Russia for almost 90 years, has challenged the former culture of "all embracing ... consistently democratic system of public education (Skatkin \& Tsov'janov, 1994: p. 52). The rapid shift toward a totally different set of pedagogical values and methods, which would benefit an individual learner and teacher, re-orientation to market-based approaches of system's management, required Russian faculty to change their educational philosophy and quickly adapt the new policy directions. In this sense, I argue that an adaptation of creative education policy in modern Russia can be viewed in line with sociocultural frameworks that praise contextual nature of policy research and focus on the culturally sensitive nature of curricular implementation.

Early sociologists have identified some of the policy implementation aspects that resonated with the cultural view of organizational changes, for example, in their discussions of policy as a way to enhance social reproduction (Bourdieu, 1990) and exercise social powers (Foucault, 1983). Most recently, Nederveen Pieterse (2009) drew attention to the "increasing silence of cultural differences” (p. 43) in sociological discourses of globalization by distinguishing three positions on cultural differences: cultural differentialism, cultural convergence, and cultural hybridization. He pointed out that "the clash between cultural diversity and globalization may well be considered a creative clash” (p. 60), as the awareness of cultural differences has been growing and it can be approached as a major function of globalization. My proposed model of the university restructuring follows on Nederveen Pieterse's taxonomy of cultural diversity. Placed within a globalization framework, the university under re-structuring can be viewed as a "hybrid formation", where the "hybrid" aspects concern the participants' experiences and interpretations of the re-structuring processes. Illustrating the "hybridity" of the university restructuring, the culturally sensitive model of a curricular adaptation takes into account diverse logics and mixed interpretations of all the stakeholder of restructuring. Approached this way, university re-structuring appears as a constructive, rather than a destructive (Beck, 2001) process, capable of increasing the range of organizational choices. The plurality of organizational choices might lead to different forms of cooperation, both local and international (Chan, 2004), among faculty and also at the level of university administration.

The insights of the cultural diversification framework can be applied to the second feature of the resulted model, the nonlinearity of the curricular education policy enactment in Russian university classrooms. Approaching a mandatory implementation of the creative education policy agenda with a baggage of cultural beliefs and knowledge of their traditional educational systems, faculty and students simply may not be fully equipped to meet challenges of the curricular adaptation. Considering the significance of cultural diversification in policy implementation processes, my findings suggest a methodological importance of keeping the research emphasis on the "implementators", people who shape and unfold the policy, rather than policy itself.

The second feature of the model, a non-linearity of the curricular education policy enactment, follows the recent developments of the education policy implementation research that draw on methodological and conceptual complexity of "implementability”. Honig (2006) points out the complexity of policy dynamics and describes new directions of policy studies on “implementability” as follows:

Implementability... [is] the product of interactions between policies, people, and places - the demands specific policies place on implementers; the participants in implementation and their starting beliefs, knowledge, and other orientations toward policy demands; and the places or contexts that help shape what people can and will do. Implementation research should aim to reveal the policies, people, and places that shape how implementation unfolds and provide robust, grounded explanations for how interactions among them help explain implementation outcomes. The essential implementation question then becomes not simply "what's implementable and works" but what is implementable and what works for whom, where, when, and why? (p. 2).

Building on Honig's perspective, I suggest that the resulted creative education policy implementation model can be viewed as a complex process and a product of interactions among the policy's structures, implementers, and the environment. The 
three aspects of the resulted model—organization, environment, and relation-reflect on this three-folded definition of the creative education policy implementation by keeping the research focus on the interdependent complexity of the involved "people, policies, and places," (Honig, 2006). From this perspective, my model also complements the existing policy implementation research models (e.g. "communication model” by Goggin, Bowman, Lester, \& O’Toole, 1990)

By shifting the focus of the study toward a complexity of the policy implementation process and elements, I address the challenge of the perpetual discrepancy between educational policy goals and classroom practices, which is well defined in the policy research. Built on a premise that educational policies are rarely consistent with teachers' classroom practices, most of the policy studies (Blignaut, 2006) draw on the "implementation problem” (McLaughlin, 2000) of discrepancy between policy and its practical implementation. The results of my study suggest a different approach to a discrepancy problem of implementation, by focusing on the non-linearity of the implementation process, particularly, its organization, environment, and relation aspects. This approach allows deeper insights into "how policy is interpreted and transformed at each point in the process, and ... the response of the individual at the end of the line” (p. 72). The non-linear approach to the curricular policy implementation challenges a common research premise of a well-established university infrastructure with a steady curricular supply base for implementing the creative education policy in Russian universities. The feature of non-linearity accounts for different levels of chaos in which the creative education policy emerged in the post-Soviet university environments and considers the unequal educational contexts that Russia has inherited from its Imperial and Soviet stages of educational restructuring.

The rapid shift of the Russian educational system to its new ideological, systemic, and economic stages, revealed the essentials of the creativity idea that forms its conceptual core across cultures. The first is that creativity appears to have been a critical component of educational inquiries in developmental psychology, educational philosophy, and sociology for many years and across all major scientific schools and cultures. Regardless of their origins, theories of creativity include objective, symbolic, individual, and social components that are integrated under a larger umbrella of a specific culture. These components appear to be a prerequisite for any empirical exploration of creativity in culturally different educational environments. A second universal feature of creativity is that, in its most general understanding, it is viewed as a holistic and continuous state of human and social developments that are guided by the universal rules of natural and social evolvements. These larger notions of creativity project themselves into different phenomenological worlds, where they manifest as specific constructs, forms, policies, and structures of a particular educational system.

The aspects of creativity theory, which are specific to the West, concern empirical approaches that Western scientists employ to study the phenomena. Guided by ideas of pragmatism, Western empirical models of creativity include domains of creative processes, products, and environments at the individual or a group levels. In contrast, Russian empirical traditions approach creativity in all its universality, treating it as original, self-sustaining, and dynamic phenomenon that can be observed and experienced, rather that induced and organized. Scientific investigations of creativity in Russian academic culture, there- fore, deal with a much broader range of creativity manifestations at individual and social levels. Following this approach, the empirical studies are concerned with the practical issues of effective problem-solving, freedom of self-realization, and creative dialogues, as well as theoretical accounts of creativity.

\section{Conclusion}

The recent re-structuring of the Russian HE system aims to quickly overcome centuries of educational traditions and place Russian universities on a competitive path of the market economy. Responding to the demands for building a "creative educational system”, the Education Law 2012 required the Russian universities to adapt new curricular programs, modules, and methodologies. My study of the "creative education” Sustainability module in two Russian universities provided insights of the cultural barriers to the policy implementation and suggested three categories of the curricular implementation (organization, environment, and relation). Two important and theoretically grounded features of the resulted model included the culturally sensitive nature of the curricular adaptation and non-linearity of the policy implementations in the university classrooms. These findings outlined the need to shift the organizational focus of policy studies toward frameworks concerned with complexity, contextuality, and cultural sensitivity of policy implementations for future studies on policy "implementation dilemma" in university classrooms.

\section{REFERENCES}

Arich, E. (2008). What is creative education? In E. Arich (Ed.), The art of creative thinking (pp. 1-13). Moscow: Mir.

Beck, U. (2001). What is globalization? Cambridge: Polity.

Blignaut, S. (2006). Teachers' interpretation and enactment of curriculum policy. Frankfurt: VDM Verlag.

Bourdieu, P., \& Passeron, J. (1990). Reproduction in education, society, and culture (2nd ed.). Thousand Oaks, CA: Sage.

Butterfield, K., Reed, R., \& Lemak, D. (2004). An inductive model of collaboration from the stakeholder's perspective. Business and Society, 43, 162-195. http://dx.doi.org/10.1177/0007650304265956

Chan, W. (2004). International cooperation in higher education: Theory and practice. Journal of Studies in International Education, 8, 32-55. http://dx.doi.org/10.1177/1028315303254429

Cresswell, J. (2003). Research design: Qualitative, quantitative, and mixed method approaches (2nd ed.). Thousand Oaks, CA: Sage.

De Ven, A., \& Huber, G. (1990). Longitudinal field research methods for studying processes of organizational change. Organization Science, 1, 213-219. http://dx.doi.org/10.1287/orsc.1.3.213

Dill, D. (1997). Higher education markets and public policy. Higher Education Policy, 10, 167-185. http://dx.doi.org/10.1016/S0952-8733(97)00011-1

Dill, D., \& Sporn. B. (1995). The implications of a postindustrial environment for the university: An introduction. In D. Dill, \& B. Sporn (Eds.), Emerging patterns of social demand and university reform: Through a glass darkly (pp. l-19). Oxford: Pergamon.

Foucault, M. (1983). The subject and power. In H. Dreyfus, \& P. Rabinow (Eds.), Michel Foucault: Beyond structuralism and hermeneutics (2nd ed., pp. 208-226). Chicago, IL: University of Chicago.

Goggin, M., Bowman, A., Lester, J., \& O’Toole, L. (1990). Implementation theory and practice: Toward a third generation. Glenview, IL: Scott Foresman.

Gordashnokov, V., \& Osin, A. (2009). Education and health of medical college students. Moscow: Academy of Natural Sciences.

Gumport, P. (2000). Academic restructuring: Organizational change and institutional imperatives. Higher Education: The International Journal of Higher Education and Educational Planning, 39, 67-91. 


\section{T. SAVELYEVA}

http://dx.doi.org/10.1023/A:1003859026301

Guilford, J. (1950). Creativity. American Psychologist, 5, 444-454. http://dx.doi.org/10.1037/h0063487

Honig, M. (2006). Complexity and policy implementation: Challenges and opportunities for the field. In M. Honig (Ed.), New directions in education policy implementation: Confronting complexity (pp. 1-22 ). Albany, NY: The State University of New York.

Lawler, E., \& Yoon, J. (1993). Power and the emergence of commitment behavior in negotiated exchange. American Sociological Review, 58, 465-481. http://dx.doi.org/10.2307/2096071

Lonchakov, A. (2004). Reforms of law and polytechnic higher education systems: Continues typologies and creative education. In T. Gomza (Ed.), Issues of higher education (pp. 53-55). Khabarovsk: KGTU.

Lǽggard, J., \& Bindslev, M. (2006). Organizational theory. Frankfurt: Ventus.

Marginson, S. (1993). Education and public policy in Australia. Melbourne, Vic: Cambridge University. http://dx.doi.org/10.1017/CBO9780511559389

McLaughlin, M. W. (2000). Listening and learning from the field: Tales of policy implementation and situated practice. In A. Hargreaves, A. Lieberman, M. Fullan, \& D. Hopkins (Eds.), International handbook of educational change (pp. 70-84). Boston, MA: Kluwer Academic.

Meyer, A., Brooks, G., \& Goes, J. (1990). Environmental jolts and industry revolutions: Organizational responses to discontinuous change. Strategic Management Journal, 11, 93-110.

Miles, M., \& Huberman, M. (1994). Qualitative data analysis: An expanded sourcebook (2nd ed.). Thousand Oaks, CA: Sage.

Nederveen Pieterse, J. (2009). Globalization and culture: Global mélange. Lanham: Rowman \& Littlefield.

Pollitt, C. (1990). Managerialism and the public services: The Anglo-American experience. Oxford: Basil Blackwell.

Pusey, M. (1991). Economic rationalism in Canberra: A nation building state changes its mind. Melbourne, Vic: Cambridge University.

Savelyeva, T. (2013). Toward a conceptual synthesis and ecological approach to case studies of curricular innovation implementation and university restructuring in Russian HE. International Journal of Higher Education, 2, 228-237.

http://dx.doi.org/10.5430/ijhe.v2n4p228

Schwartzman, R. (1995). Students as customers: A mangled managerial metaphor. ERIC Document Reproduction Service No. ED 383 022, Charlotte, NC: Carolinas Speech Communication Association.

Skatkin, M., \& Tsov'janov, G. (1994). Nadezhda Konstantinovna Krupskaya. In J. Tedesco, \& Z. Morsy (Eds.), Thinkers on education, Vol. 3 (pp. 49-60). Paris: UNESCO.

Smart, D., \& Hitt, M. (1994). A mid-range theory regarding the antecedents of restructuring types: An integration of agency, upper echelon and resource-based perspectives. In P. Shrivastava, A. Huff, \& J. Dutton (Eds.), Advances in strategic management, Vol. 10A (pp. 159-186). Greenwich, CT: JAI.

Welch, A. (1998). The cult of efficiency in education: Comparative reflection on the reality and rhetoric. Comparative Education, 24 157-175. http://dx.doi.org/10.1080/03050069828252 